\title{
Myocardial triglyceride content in patients with left ventricular hypertrophy: comparison between hypertensive heart and hypertrophic cardiomyopathy
}

\author{
Eiryu Sai ${ }^{1 *}$, Kazunori Shimada ${ }^{1}$, Takayuki Yokoyama ${ }^{1}$, Shuji Sato ${ }^{2}$, Makoto Hiki ${ }^{1}$, Tetsuro Miyazaki ${ }^{1}$, Shigeki Aoki ${ }^{3}$, \\ Hiroyuki Daida ${ }^{1}$
}

From 18th Annual SCMR Scientific Sessions

Nice, France. 4-7 February 2015

\section{Background}

Proton magnetic resonance spectroscopy $\left({ }^{1} \mathrm{H}\right.$-MRS) enables to assess the myocardial triglyceride (MTG) content, which is reported to be associated with cardiac dysfunction and morphology accompanied by metabolic disorder and cardiohemodynamic status. However, clinical usefulness of measurement of MTG content in patients with left ventricular hypertrophy $(\mathrm{LVH})$ has not been investigated.

\section{Methods}

To quantify MTG content, we performed ${ }^{1} \mathrm{H}$-MRS in 39 subjects with LVH. Left ventricular (LV) function was measured by cardiac magnetic resonance imaging. We divided into HHD and HCM groups on the basis of histology and/or the late gadolinium enhancement pattern.

\section{Results}

The MTG content was significantly higher in the HHD group than in the HCM group $(2.14 \pm 1.29 \%$ vs $1.09 \pm$ $0.70 \% ; \mathrm{P}=0.0009)$. In the HCM group, MTG content was significantly associated with LV mass $(r=-0.41, \mathrm{P}<0.04)$. In the HHD group, MTG content was significantly associated with LV end-diastolic volume, stroke volume, and cardiac output $(r=-0.63, r=-0.76, r=-0.62$, all: $\mathrm{P}<0.05)$.

\section{Conclusions}

The MTG content of HCM was negatively correlated with LV mass but not LV function. These results suggested

${ }^{1}$ Cardiovascular Medicine, Juntendo University, Graduate School of Medicine, Tokyo, Japan

Full list of author information is available at the end of the article that the measurement of MTG content by ${ }^{1} \mathrm{H}$-MRS might be useful for grading HCM pattern as well as distinguishing between HCM and HHD.

\section{Funding}

None.

\section{Authors' details}

'Cardiovascular Medicine, Juntendo University, Graduate School of Medicine, Tokyo, Japan. ${ }^{2}$ Radiology, Juntendo university hospital, Tokyo, Japan.

${ }^{3}$ Radiology, Juntendo university, graduate school of medicine, Tokyo, Japan.

Published: 3 February 2015

doi:10.1186/1532-429X-17-S1-P246

Cite this article as: Sai et al:: Myocardial triglyceride content in patients with left ventricular hypertrophy: comparison between hypertensive heart and hypertrophic cardiomyopathy. Journal of Cardiovascular Magnetic Resonance 2015 17(Suppl 1):P246.

Submit your next manuscript to BioMed Central and take full advantage of:

- Convenient online submission

- Thorough peer review

- No space constraints or color figure charges

- Immediate publication on acceptance

- Inclusion in PubMed, CAS, Scopus and Google Scholar

- Research which is freely available for redistribution 